\title{
¿IGUALDAD O IGUALITARISMO? DOS PERSPECTIVAS ACERCA DE LA JUSTICIA*
}

\author{
Felipe Schwember \\ Universidad Adolfo Ibáñez
}

\begin{abstract}
RESUMEN: En el presente trabajo se examinan someramente algunas de las premisas sobre las que descansan las teorías igualitaristas más aceptadas. Se examinan también algunos de los argumentos que suelen esgrimirse desde diferentes frentes en favor del igualitarismo o en contra de la economía de mercado. Contra todos ellos se defiende una teoría histórica de la propiedad inspirada en la teoría de la propiedad de Kant y en la teoría del título válido de Robert Nozick. Se sostendrá, empero, que, bien entendida, la teoría del título válido exige la instauración de un Estado subsidiario, lo que, en esa misma medida, conduce a posiciones "suficientaristas".

Palabras Clave: liberalismo, igualitarismo, justicia distributiva, justo título, "suficientarismo".
\end{abstract}

FeliPe Schwember. Licenciado en derecho y en filosofía por la Universidad Católica de Chile. Doctor en filosofía por la Universidad de Navarra. Profesor del Centro de Investigación en Teoría Social y Política de la Escuela de Gobierno, Universidad Adolfo Ibáñez. Email: felipe.schwember@uai.cl.

* Versión revisada de la conferencia realizada en el simposio “¿Es la desigualdad un problema político?", llevado a cabo el martes 6 de septiembre de 2016 en el CEP. El autor expresa: "Agradezco los comentarios, correcciones y sugerencias de Alejandro Vigo, Gonzalo Cordero, Miguel González y Marcel Oppliger. El presente trabajo es parte del proyecto Fondecyt regular (Chile) n. ${ }^{\circ} 1160982$ titulado 'Crítica y recepción de las utopías y del utopismo en el liberalismo libertario y en el liberalismo socialdemócrata del siglo XX: Popper, Hayek, Nozick y Rawls"”. 


\section{EQUALITY OR EGALITARIANISM? TWO PERSPECTIVES ON JUSTICE}

ABSTRACT: In this paper it will be briefly discussed some of the premises on which some of the most accepted theories egalitarians rest on. It will be also examined some of the arguments usually be put forward on several fronts in favour of egalitarianism or against the free market economy. Against all of them it will be supported a historical theory of property inspired in Kant's theory of property and in Nozick's entitlement theory. It will be argued, however, that properly understood, the entitlement theory requires the establishment of a subsidiary State, which, to the some extent, leads to suficientarianism.

KEYwORDs: liberalism, egalitarianism, distributive justice, entitlement, suficientarianism.

\section{INTRODUCCIÓN: RECONOCIMIENTO, DESIGUALDAD Y DESIGUALDAD MATERIAL}

\footnotetext{
E 1 concepto de igualdad tiene tantos sentidos que cualquier reE flexión acerca de su importancia para la teoría y práctica política necesita comenzar con el esbozo de al menos ciertas distinciones elementales.
}

En un primer sentido, "igualdad" hace referencia a la igualdad ante la ley o al deber de dispensar igualdad de trato a las personas. En este sentido, la "igualdad" se opone a los privilegios, a la lex privata en virtud de la cual alguien es beneficiario de un trato diferente y mejor del que se dispensa al común de la gente. Se opone también a la discriminación arbitraria; esto es, al trato indebido que se le da a alguien en razón de su raza, sexo, confesión religiosa, clase social o cualquier otro rasgo, innato o adquirido, que sea irrelevante a la hora de juzgar los merecimientos de una persona.

Esta última forma de desigualdad puede extremarse de modo tal que no sólo se escatime a una persona el trato que como tal se le debe en una circunstancia concreta (por ejemplo, a la hora de decidir si se la contrata o no para un trabajo), sino que se le niegue como persona en general. Éste es el caso más extremo de desigualdad, pues supone cosificar al otro o al menos la pretensión de reificarlo totalmente (Honneth 2007). 
Fichte ha tratado brillantemente este problema al momento de elaborar su propia teoría del derecho (1971, §§ 3 y 4). En ella defiende que el reconocimiento recíproco - esto es, el trato por el que dos individuos se demuestran respeto a la racionalidad y dignidad del otro- constituye el acto por el cual se instaura cualquier relación jurídica.

Tomada como "reconocimiento recíproco", la igualdad constituye no sólo el acto fundante de toda relación jurídica, sino, más aún, una condición de posibilidad del arribo a la propia autoconciencia, del despliegue y actualización de los rasgos propiamente humanos, pues para llegar a ser verdaderamente un individuo racional necesito que los demás me traten como persona.

Se contraponen por tanto a esta segunda noción de igualdad, a la igualdad como "reconocimiento", aquellas concepciones que sostienen que existen "por naturaleza" individuos inferiores a otros o, en fin, aquellas concepciones que tienden a estigmatizar o criminalizar a ciertas personas o grupos de personas, desdibujando su humanidad de modo de alentar el odio en su contra; seguramente, no puede odiarse con suficiente encono a alguien a menos que se lo considere como lo totalmente otro, lo radicalmente distinto de mi persona.

Respetar la igualdad como "reconocimiento" significa, entonces, respetar la igual humanidad del otro. En este sentido, por tanto, la igualdad no es sólo un aspecto particular, más o menos deseable del derecho, sino que también su condición de posibilidad más elemental.

Aunque Fichte no parece considerar que el reconocimiento de una persona pueda ser parcial (o se considera a alguien persona o no se lo reconoce, pero no hay puntos intermedios en esto), su idea del reconocimiento recíproco ha sido adoptada, a través de Hegel, en la filosofía posterior que ha considerado que "la lucha por el reconocimiento" puede ofrecer una perspectiva fructífera para entender el significado de muchas de las luchas sociales y políticas contemporáneas (Honneth 1997).

Así, por ejemplo, las luchas en favor de la extensión de los derechos que llevan a cabo minorías (étnicas, sexuales, etc.) se podrían entender como luchas por el reconocimiento de otros miembros de la sociedad. Se trataría, en estos casos, de remediar el déficit de reconocimiento que padecen los individuos que pertenecen a dichos grupos y a los que se menosprecia precisamente por formar parte de ellos.

La "lucha por el reconocimiento" puede entenderse de diversas formas, por lo que a su extensión se refiere. Aquí no me detendré en 
este problema. Sólo diré que, me parece, muchas de esas reivindicaciones tienen por objeto erradicar o desactivar las mecanismos de discriminación imperantes en alguna sociedad, ya sea que se trate de mecanismos formales (es decir, consagrados en la ley) o informales (prácticas sociales), y que son causa de injusticias históricas. En este sentido, creo que tales teorías se pueden entender más como un intento de articular una justificación en favor del deber de procurar una reparación a las víctimas de tales injusticias que como un alegato en favor de la igualdad material propiamente tal.

Esta distinción nos permite arribar al tercer sentido de "igualdad/ desigualdad" que es posible distinguir y que constituye el objeto principal de esta exposición. Me refiero a la igualdad material o económica. En la discusión contemporánea se ha llamado la atención acerca de la relación que existe entre esta forma de desigualdad y el reconocimiento debido a otros (Fraser y Honneth 2006).

Ya el propio Fichte creía que el concepto de reconocimiento que él introdujo para fundamentar el derecho permitía ir más allá de lo que podemos denominar la igualdad formal para avanzar hacia una concepción material de la igualdad. El reconocimiento recíproco es el fundamento, a su entender, de cualquier institución jurídica, y la propiedad, evidentemente, no es la excepción. Por tanto Fichte entiende que sólo existe realmente propiedad desde el momento en que tú me reconoces - en el sentido de "me concedes"- lo que yo vaya a tener como propio a cambio de que yo haga lo mismo con lo que vayas a tener tú. No es de extrañar que su teoría del derecho termine en una concepción fuertemente igualitaria en este tercer sentido de que he hablado, es decir, en lo que concierne a la igualdad material o económica.

Pongo nuevamente a Fichte como ejemplo porque en su filosofía anticipa, hasta cierto punto, algunas de las posiciones más prominentes del debate contemporáneo acerca de la justicia. Entre ellas ha habido, como decía, una importante discusión en torno a la relación entre justicia distributiva y reconocimiento. Se ha discutido si acaso el problema del reconocimiento es o no diferente del problema estrictamente distributivo o - para ponerlo en términos de lo que aquí nos convoca- si acaso es o no realmente diferente del problema de la (des)igualdad material o, más precisamente, de los grados de desigualdad material que son moralmente admisibles. 
Gran parte de las dificultades que presenta esta discusión tiene que ver con la porosidad de las categorías de "reconocimiento" y "distribución", y con la ambigüedad que en la práctica presentan. Con todo, permítaseme que haga una distinción, al menos provisional, entre la desigualdad material que es resultado del déficit de reconocimiento de aquella que obedece a otras razones, digamos, puramente distributivas. $\mathrm{O}$, más precisamente, permítaseme asumir que algunas desigualdades materiales son consecuencia de un déficit de reconocimiento mientras que otras no lo son.

Quizá podría argumentarse que no existe desigualdad económica que no sea consecuencia del déficit de reconocimiento, sea que éste se exprese de modo formal (en las leyes que, por ejemplo, imponen prohibiciones arbitrarias a unos en favor de otros) o informal; o, en fin, podría argumentarse que la desigualdad que existe por esta causa es marginal.

Concedo de buen grado que eso puede ser así. Pero como de todos modos ésa no es la premisa de la que han partido las teorías igualitaristas más difundidas actualmente, yo también prescindiré, al menos momentáneamente, de ella a la hora de examinar críticamente tales teorías.

Por tanto, me referiré, en primer lugar, a las desigualdades materiales que no son consecuencia directa de un déficit de reconocimiento, con el fin de elaborar una crítica a las teorías igualitaristas contemporáneas. Como espero dejar de manifiesto, los presupuestos de tales teorías adolecen de graves problemas que, a mi juicio, dejan la carga de la prueba del lado de quienes las profesan.

Enseguida, me referiré a la teoría de la justicia que, creo, es la correcta $\mathrm{o}$, al menos, mejor que las teorías igualitaristas anglosajonas que hoy gozan de tan amplia aceptación. Siguiendo a Robert Nozick, denominaré a esta teoría "histórica" y desde la perspectiva abierta por ella abordaré dos cuestiones adicionales: el problema de la necesidad y el problema del "lucro", tan recurrente en Chile desde 2011. Sostendré que, bien entendida, una teoría histórica como la de Nozick debiera comprometerse con el alivio de aquellos que padecen necesidad y que ese compromiso debiera traducirse en la defensa de un Estado subsidiario. Abordaré, luego, algunas de las premisas que, creo, subyacen al eslogan en contra del lucro para desestimarlas. Sostendré que en los tratos libremente celebrados existe un reconocimiento mutuo y que dicho reconocimiento se expresa, precisamente, en el pago que las partes se hacen recíprocamente. 
Espero que en el hilo de toda la exposición quede claro que la teoría de la justicia que aquí defenderé permite, hasta cierto punto, explicar - en el sentido de validar o refrendar - las demandas de igualdad originadas en un déficit de reconocimiento, especialmente cuando dicho déficit ha ido unido a una injusticia histórica. El ethos de tolerancia en el que descansa la teoría liberal de la justicia que aquí defiendo contribuye a desmontar los mecanismos de discriminación, ya directamente, en la medida en que defiende una estricta igualdad de trato, ya indirectamente, en la medida en que priva de refuerzo legal e institucional a las prácticas de discriminación social.

Espero, en fin, que quede claro que, conforme al paradigma definido por la teoría de la justicia aquí defendida, la situación ideal es que tales déficit de reconocimiento se remedien en el sentido de que las diferencias que los suscitan lleguen a ser irrelevantes (por ejemplo, que ya nadie repare en el color de la piel, la religión o la orientación sexual de la otra persona a la hora de decidir si debe tener tratos con ella o no). Me gustaría pensar que la teoría liberal de la justicia que aquí presento contribuiría a alcanzar ese estado de cosas, en la medida en que delimita las bases para el respeto mutuo y permite a los individuos elegir libremente su modo de vida mientras no impidan a los demás hacer lo propio. Ese es, después de todo, el desiderátum de toda utopía liberal.

\section{LAS TEORÍAS IGUALITARISTAS CONTEMPORÁNEAS}

En el mundo filosófico anglosajón se ha producido una abundante literatura en favor de la igualdad material. Tan vasta es que seguramente no exageraría quien dijera que el problema de la igualdad material ha llegado a ser una subespecialidad por derecho propio dentro de la filosofía política. ${ }^{1}$

Con todo, y pese a su variedad, todas esas teorías parten básicamente de alguna de las siguientes dos asunciones que pueden rastrearse hasta la filosofía de John Rawls — cuando no a la de Rousseau-y que, creo, son erróneas. La primera es que las desigualdades que son resultado de las contingencias naturales (como la posición social y las diferen-

${ }^{1}$ Para una visión sinóptica de la discusión acerca del igualitarismo, ver Hirose (2015). 
cias de talentos) son arbitrarias desde el punto de vista moral y que, en consecuencia, deben compensarse.

La segunda es tratar los bienes que son producto de la cooperación social como si estos fueran propiedad colectiva. Me refiero, evidentemente, a la crítica que Nozick dirige a las teorías distributivas no históricas de tratar los bienes como si fueran maná caído del cielo.

\subsection{El problema de la "lotería natural"}

Veamos a la primera de estas asunciones. En su célebre Teoría de la justicia, Rawls afirma:

Primeramente podemos observar que el principio de diferencia [es decir, el segundo de los principios de justicia de su propia teoría] da algún valor a las consideraciones particularizadas por el principio de compensación. Este principio afirma que las desigualdades inmerecidas requieren una compensación; y dado que las desigualdades de nacimiento y de dotes naturales son inmerecidas, habrán de ser compensadas de algún modo. (Rawls 2003, 103)

Un poco más adelante, añade: "Nadie merece una mayor capacidad natural ni tampoco un lugar inicial más favorable en la sociedad" (Rawls 2003, 104). O, para decirlo aun con otras palabras, tales aspectos "del mundo social" parecen, desde un punto de vista moral, "arbitrarios" (Rawls 2003, 28).

Esta concepción suscita diferentes dificultades. Una tiene que ver con el problema del merecimiento. ¿Qué significa aquí que las dotes naturales no sean "merecidas"? Y, además, ¿ante quién deberían serlo, exactamente?

Por una parte, la afirmación de Rawls es cierta, evidentemente: nadie merece a priori una posición mejor que la de otro. Sin embargo, por otra, es falsa, en la medida en que tiende a moralizar una situación - la distribución de las dotes naturales - que no es objeto de elección alguna y, por consiguiente, no susceptible de juicio moral.

Quizás la dificultad estriba, respecto del caso concreto que preocupa a Rawls de la posición social y las dotes naturales, en la oposición binaria "merecido-inmerecido" (o "arbitrario-justificado"), que no resulta la más feliz para examinar la situación a que da lugar la "distribución 
natural". Las dotes naturales no son ni merecidas ni inmerecidas, sino tan sólo "no merecidas", lo que es diferente. Eso significa, en buenas cuentas, que resulta improcedente exigir a alguien que dé una justificación moral de la posesión de sus propios talentos, habilidades o posición social. Esto es imposible y, como reza el adagio, "nadie está obligado a lo imposible". Sin embargo, el hecho de que sea "no merecido" quiere decir también que el uso ulterior de los propios talentos y habilidades es susceptible de juicio moral: podemos comportarnos de mejor o peor manera respecto de ellas (y aquí uno podría pensar en ciertas enseñanzas tradicionales, como, por ejemplo, la parábola de los talentos, la parábola del rico Epulón y el pobre Lázaro u otras semejantes). ${ }^{2}$

Pero además hay otro problema con la perspectiva adoptada por Rawls. El esfuerzo, los hábitos, etcétera, que explican la constancia, disciplina y esfuerzo diferencial para lograr una mejor posición, ¿deben ser considerados como dotes naturales inmerecidas y arbitrarias o no? Si uno imagina que ese esfuerzo tiene, al menos parcialmente, que ser explicado por la educación recibida, el entorno social, el propio temperamento, ¿no debieran entonces considerarse tal disciplina, esfuerzo, etcétera, como, a su vez, no merecidos? ${ }^{3}$ No es de extrañar que Nozick haya dicho que la estrategia de Rawls de argumentar en favor de la

${ }^{2}$ Existe un cuento sufí que relata la historia de tres niños que salieron una mañana a recoger nueces. Cuando llegó el momento de hacer la distribución cayeron en cuenta de que estaban en un problema, porque habían dejado todas las nueces que cada uno había recogido en una misma cesta. Como no podían ponerse de acuerdo acerca de cuántas le correspondían a cada uno, decidieron ir donde el anciano más sabio del pueblo y le dijeron: "Reparte estas nueces entre nosotros tal como Alá lo haría". El sabio entonces procedió a dar 10 nueces a uno, 30 a otro y 60 al tercer chico. Entonces el segundo de ellos se quejó de la desigual repartición y dijo: "Pero te pedimos que repartieras tal como lo habría hecho Alá". El sabio entonces respondió: "Y eso es precisamente lo que he hecho". Si uno quiere descartar la hipótesis de que Dios es injusto, entonces no le queda más remedio que conjeturar acerca de las razones por las que Dios haría una repartición semejante. Habida cuenta de las múltiples distopías que se han escrito acerca de las sociedades que han intentado construirse sobre la igualdad estricta, uno podría especular que Dios ha hecho esa distribución desigual para evitar sociedades como ésas. Conjugar libertad e igualdad no es fácil, y Rawls tiene el mérito de haber elaborado una teoría que ofrece una alternativa al respecto.

${ }^{3}$ Zaitchik afirma que el razonamiento de Rawls acerca de las dotes naturales es recursivo y conduce al absurdo de que nadie merece nada. Sher ofrece una interpretación del argumento de Rawls que, cree, evita esta objeción de Zaitchik. Compárese Zaitchik (1977) y Sher (1987, 25 y ss.). 
igualdad apelando a la arbitrariedad de las dotes naturales, etcétera, resulte peligrosa por lo que a la preservación y respeto de la autonomía de los individuos se refiere:

Esta línea de argumentación puede bloquear la introducción de decisiones y acciones autónomas de una persona (y sus resultados) sólo atribuyendo todo lo que es valioso en la persona a ciertas clases de factores completamente "externos". De esta manera, denigrar la autonomía de una persona y la genuina responsabilidad de sus acciones es una línea arriesgada de tomar para una teoría que, de otra manera, desea reforzar la dignidad y el respeto propio de seres autónomos. (Nozick 1988, 211)

No obstante, no quiero ser injusto con Rawls. Él mismo dice, después de todo, que:

La distribución natural no es ni justa ni injusta, como tampoco es injusto que las personas nazcan en una determinada posición social. Éstos son hechos meramente naturales. Lo que puede ser justo o injusto es el modo en que las instituciones actúan respecto a estos hechos. (Rawls 2003, 104)

Esto, sin embargo, probablemente sea una prueba de que él trata este asunto de modo más bien confuso. Pero el tratamiento moderado - o ambiguo, si se prefiere - que da Rawls al problema de la legitimidad de las dotes naturales termina en posturas disparatadas en sus epígonos. Me refiero a los así llamados "igualitaristas de la suerte", que se sienten en la necesidad de corregir lo que consideran una especie de "injusticia cósmica", proponiendo para ese fin medidas como la subvención de los surfistas jóvenes que pueden trabajar pero no quieren hacerlo (Van Parijs 1996, 117 y ss.) (respecto de gente en situación como ésa, ¿no es acaso más justa la postura de San Pablo que dice que el que no quiera trabajar que no coma?); la subvención de los gustos caros de aquellos que no se los pueden costear, en el entendido de que nadie tiene, a fin de cuentas, la culpa de sus propios gustos (Cohen 2011, 20 y ss.) (¿y se supone que a esto lo debemos considerar una especie de marxismo?), y otras posturas por el estilo.

Las posturas igualitaristas desarrolladas al amparo de estas premisas — el así llamado igualitarismo de la suerte — han caído en tales 
inverosimilitudes, en tales extravagancias, que no es de extrañar que otra autora de vocación igualitaria (y más cercana a Rawls) haya dicho que toda la literatura igualitarista del último tiempo podría haber sido escrita por autores secretamente conservadores que querían desprestigiar al igualitarismo (Anderson 2016, 45). Ciertamente, no deja de ser significativo que una filósofa que comparte los fines del igualitarismo haya expresado un juicio tan lapidario en contra del igualitarismo de la suerte.

La otra dificultad que enfrentan posturas como las de Rawls tiene que ver, como decíamos, con el presupuesto que subyace a la idea de que las diferencias naturales resultan arbitrarias; esto es, que tales diferencias no pueden ser justificadas desde un punto de vista moral. La pregunta que esta exigencia inmediatamente suscita es: ¿justificables ante quién? ¿Ante los demás, tal vez? Ésta es la asunción que subyace a la afirmación de Rawls, puesto que él afirma que el principio de diferencia "representa (...) el acuerdo de considerar la distribución de talentos naturales, en ciertos aspectos, como un acervo común, y de participar en los beneficios de esta distribución, cualesquiera que sean" (Rawls 2003, 104). ${ }^{4}$ Pero, ¿por qué uno debería poder dar cuenta de sus propios talentos o dotes naturales a los otros? ¿Es éste verdaderamente un deber que se sigue de la necesidad de la cooperación social? Por otra parte, ¿esta asunción no nos obliga a considerar las dotes naturales como bienes colectivos? ${ }^{5}$ La afirmación de Rawls de que los talentos naturales deben ser considerados "en ciertos aspectos" como parte de un "acervo común", convierte el uso y aprovechamiento de dichos talentos en una cuestión de interés público. Así, tanto la diligencia como la negligencia de los individuos dejan de ser un problema puramente personal para pasar a ser un bien colectivo, pues a todos concierne el uso de los bienes colectivos.

${ }^{4} \mathrm{Y}$ si ésta es efectivamente la asunción subyacente, ¿es tan claro que individuos racionales y mutuamente desinteresados e ignorantes de sus circunstancias particulares adoptarían el principio de diferencia? ¿Consentiría usted en dar a los demás derechos sobre su propia persona?

${ }^{5}$ Rawls, entiende, sin embargo, que su teoría se aplica a la estructura básica de la sociedad (es decir, instituciones sociales) y no a los individuos particulares. ¿Evita esto críticas como las de Nozick? Difícilmente, en la medida en que el mismo Rawls ha retrotraído el problema de la distribución a los talentos y capacidades individuales. Después de todo, no hay talentos ni capacidades colectivas. 
Podrían mencionarse otras dificultades que se siguen del hecho de considerar los talentos naturales como arbitrarios e inmerecidos. El primero tiene que ver con el papel que le cabe al mérito en la distribución de los bienes. Rawls sostiene que el mérito moral no puede ofrecer tal criterio. Creo que lleva razón, pero no por los motivos que él aduce. Creo que el problema tiene que ver con el hecho de que Rawls está pensando en una noción unificada, digamos así, del mérito.

Evidentemente, cualquier concepción unificada de mérito como criterio de intercambio - por ejemplo, el esfuerzo, la virtud moral, el talento, etcétera - sería no sólo incompatible con una teoría liberal de la justicia, sino, además, impracticable. ${ }^{6}$ Sin embargo, el mérito aún puede adoptarse como criterio de distribución si, como en el caso de una economía libre, se abandona la idea de adoptar una noción unificada de mérito y, en su lugar, se deja a cada individuo juzgar el mérito y valor de las contribuciones de los demás.

¿Podría endilgarse esta concepción del mérito a Rawls para evitarle, al menos, este problema? Tal vez no, pues independientemente de las razones sistemáticas que pudieran existir, un sistema que distribuya únicamente en base a las meras preferencias individuales todavía necesita reconocer el mérito de aquel que ha sabido satisfacer mejor las preferencias de otros. ${ }^{7}$

Otro problema adicional es el de las medidas que se pueden tomar para remediar esta pretendida arbitrariedad cósmica. En algún pasaje Rawls llega a decir que la teoría de la justicia debe anular "los accidentes de los dones naturales y las contingencias de las circunstancias sociales". ${ }^{8}$ La pregunta que esto suscita es: “¿Qué tan lejos se puede llegar en la consecución de dicha anulación? ¿En qué punto entraría

${ }^{6}$ Hume llamaba ya la atención sobre este problema $(1993,59)$. Por otra parte, quizás no esté de más añadir que teorías de la justicia como la de Tomás de Aquino tampoco apelan a una noción unificada de mérito como criterio de distribución de los bienes.

${ }^{7}$ Con todo, compárese también Rawls (2002, 107-109), donde hace distinciones importantes respecto del mérito.

8 "Una vez que nos decidimos a buscar una concepción de la justicia que anule los accidentes de los dones naturales y las contingencias de las circunstancias sociales, como elementos computables en la búsqueda de ventajas políticas y económicas, nos vemos conducidos a estos principios; expresan el resultado de no tomar en cuenta aquellos aspectos del mundo social que desde un punto de vista moral parecen arbitrarios" (Rawls 2003, 28. Énfasis añadido). 
ésta en contradicción con el principio de la igual distribución de libertades, principio que en la teoría de Rawls tiene prioridad lexicográfica sobre el principio de la igualdad? $\mathrm{Si}$, por tomar la desafortunada analogía de un ministro del actual gobierno, un niño tiene patines y otro no, ¿se le deben quitar los patines al primero para anular las diferencias inmerecidas?

Adviértase que un rawlsiano aún puede apelar in extremis a la prioridad de la libertad para evitar estas consecuencias contraintuitivas. ${ }^{9}$ Es decir, Rawls aún podría evitar esta conclusión a que su propia teoría abre camino sólo porque no es un autor estrictamente igualitarista. Para un igualitarista estricto, si no hay posibilidad de proporcionar un par de patines al niño que no los tiene, es perfectamente lícito quitárselos entonces al que sí tiene. Es decir, el igualitarismo puede, en rigor, alcanzar sus fines mejorando las condiciones de los que están peor como, si eso no es factible, empeorando la situación de los que están mejor. ${ }^{10}$ Esta conclusión mezquina demuestra que el igualitarismo estricto sólo resulta plausible cuando se lo combina con algún otro principio (por ejemplo, el de utilidad o el de la prioridad de la libertad, u otro cualquiera). ${ }^{11}$

\subsection{Del "excedente cooperativo" a la comunidad adventicia de bienes}

Revisemos ahora la siguiente asunción. Me refiero a la concepción subyacente que invariablemente adoptan los autores igualitaristas de los más diversos signos a la hora de pensar en el problema de la justicia, es decir, a la idea —o a la mera asunción, como ocurre en muchos casosde que los bienes que son producto de la cooperación social forman una suerte de patrimonio común que debe ser luego repartido.

\footnotetext{
${ }^{9}$ Eso es precisamente lo que Rawls hace (2002, 110-112).

${ }^{10}$ Esto es lo que Parfit ha denominado la "objeción de la nivelación hacia abajo" (the levelling down objection). Compárese, por ejemplo, Parfit (1997, 210 y ss.).

${ }^{11}$ A propósito de este problema - y sin perjuicio de la observación de Hume de que conduciría a la tiranía (Hume 1993, 60-61) —, pueden añadirse varios argumentos contra el igualitarismo estricto. Por ejemplo, abre camino a la ineficiencia como política pública, en la medida en que desacopla el bienestar de los individuos de la consecución de la igualdad; que, por lo mismo, tiende a empobrecer a la sociedad (si una sociedad no es muy próspera, cuando no rica, al igualitarismo no le quedará más remedio que igualar hacia abajo); que, además, el igualitarismo estricto constituye un fuerte disuasivo de la productividad, etcétera. Ésta, sin embargo, no es mi línea de argumentación principal.
} 
Rawls justifica esta aproximación cuando afirma que la cooperación social produce un "excedente cooperativo" cuya correcta distribución debe ser dilucidada por la teoría de la justicia. Es de suponer, por otra parte, que la línea de base que permite deslindar contribución propia del excedente cooperativo es muy baja, pues, a la larga, todos los bienes terminan siendo considerados como partes de una bolsa común que luego debe ser repartida. Permítaseme que llame a esta concepción como "comunidad adventicia de bienes", por contraposición a la concepción, predominante en la filosofía medieval y moderna, de que los bienes eran originariamente comunes y formaban, por consiguiente, una "comunidad originaria de bienes". En esta última, y como su nombre lo indica, los bienes eran desde un principio comunitarios - y "comunitarios" puede interpretarse de diferentes maneras-; en la adventicia se entiende, en cambio, que los bienes llegan a ser —en virtud de la cooperación social- "comunitarios".

Un par de ejemplos servirán para ilustrar ambas representaciones y subrayar su función en las teorías igualitaristas y, más en general, en las teorías abolicionistas de la propiedad privada (es decir, "comunistas", en un sentido amplio). Cualquier teoría que parta de alguna de estas dos representaciones acerca del origen de la titularidad de los bienes se verá forzada a adoptar una perspectiva centralista de la justicia y, por lo mismo, una preferencia por el igualitarismo en lo que a la distribución de bienes se refiere.

Por ejemplo, Proudhon en ¿Qué es la propiedad?, al momento de referirse a la prima occupatio que muchas teorías modernas de la justicia y de la propiedad veían como el modo legítimo de adquirir el dominio, dice:

Examinemos, sin embargo, la cuestión según la plantea Grotius. "En su origen, todas cosas eran comunes e indivisibles: constituían el patrimonio de todos...". No leamos más: Grotius refiere cómo esta comunidad primitiva acabó por la ambición y la concupiscencia, como a la edad de oro sucedió la de hierro, etc. De modo que la propiedad tendría su origen primero en la guerra y la conquista, después en los tratados y en los contratos. Pero, o estos pactos distribuyeron los bienes por partes iguales, conforme la comunidad primitiva, única regla de distribución que los primeros hombres podían conocer, y entonces la cuestión del origen de la propiedad se presenta en estos términos: ¿cómo ha 
desaparecido la igualdad poco tiempo después?; o esos tratados y contratos fueron impuestos por la violencia y aceptados por debilidad. (Proudhon 1985, 62)

De esta concepción acerca de la situación inicial de los bienes como objeto de un patrimonio común se sigue la consecuencia de que "la ocupación (...) impide la propiedad" (Proudhon 1985, 82). Más aún, resulta perfectamente posible sostener que, en realidad, "todo ocupante es (...) necesariamente poseedor o usufructuario" y que, como tal, "está bajo la inspección de la sociedad, y sometido a la condición del trabajo y a la ley de igualdad" (Proudhon 1985, 82).

Kropotkin, por su parte, afirma lo siguiente:

Todo se entrelaza: ciencia e industria, saber y aplicación. Los descubrimientos y las realizaciones prácticas que conducen a nuevas invenciones, el trabajo intelectual y el trabajo manual, la idea y los brazos. Cada descubrimiento, cada progreso, cada aumento de la riqueza de la humanidad, tiene su origen en la conjunción del trabajo manual e intelectual del pasado y del presente. Entonces, ¿con qué derecho alguien se apropia de la menor parte de ese inmenso todo y dice: "Esto es sólo mío y no de todos"? (Kropotkin 2010, 30) $)^{12}$

Nozick ha levantado una contundente crítica a lo que aquí he llamado comunidad adventicia de bienes. ¿Por qué — se pregunta- la cooperación social habría de producir un problema distributivo? (Nozick 1988, 184). Rawls — entre tantos otros - trata los bienes como si todos hubieran concurrido indistintamente a su producción y como si, además, las contribuciones particulares fueran además indiscernibles. Pero, ¿no resulta esta suposición arbitraria? ¿No se podría suponer que en todo el proceso de producción cada individuo ha recibido una contraprestación equivalente por su parte? El que un bien sea resultado de una producción conjunta no significa que la determinación de la contribución de cada cual sea indiscernible. Es de suponer que la contribución del operario que apretó las tuercas puede ser evaluada y retribuida del mismo modo que la contribución del ingeniero que diseñó los pla-

12 Anderson adopta una concepción similar a la de Kropotkin (Anderson 2016, 84-85). 
nos, etcétera. Ya me referiré de inmediato al problema de la evaluación, de lo que podemos denominar el "justo precio" de cada contribución. Por el momento baste concluir, siguiendo a Nozick, que, si es posible determinar el valor de cada contribución, no hay razón para asumir la comunidad adventicia de bienes que Rawls parece adoptar.

Pero éste no es el único problema que suscita la aproximación de Rawls y de otros igualitarios que también tienden a considerar los bienes como si por defecto conformaran un patrimonio común. El otro problema, tal vez peor, es que tratan además los bienes como si estos cayeran, dice Nozick, como maná del cielo (Nozick 1988, 197 y 216). Esta representación tiene su reflejo en la metáfora de la torta de la que tanto le gusta hablar a los igualitaristas: los bienes productos de la cooperación social serían como una torta y el problema es saber cómo repartirla o, si está mal repartida, rectificar la distribución. ${ }^{13}$

Sin embargo, como los bienes no aparecen espontáneamente, la metáfora de la torta de cumpleaños es perversa, porque desacopla la producción de estos bienes de los esfuerzos que otros han realizado para llevarla a cabo. Ante la persistencia con que los igualitaristas han ignorado esta crítica de Nozick, ${ }^{14}$ ¿resultaría muy arbitrario suponer que lo que se oculta detrás de su teoría de la comunidad adventicia no es otra cosa que la convicción de los igualitaristas de que los bienes son originariamente comunes? No me referiré aquí a la hipótesis de la comunidad originaria de bienes. Me contentaré con decir que, si mi suposición fuera cierta, el igualitarismo se vería en graves aprietos para sostener su propia posición: la teoría de la comunidad originaria es seguramente más difícil de sostener que la teoría de la comunidad adventicia de bienes.

\section{LIBERTAD, JUSTICIA Y MERCADO}

La afirmación de que la distribución de mercado es justa resulta ahora mismo chocante para gran parte de la opinión pública en Chile. Supongo que ello es así por, al menos, dos razones. Primero, porque los

${ }^{13}$ Kirzner llega a decir que no existe tal cosa como una torta. Véase Kirzner (1995, 57-61).

${ }^{14}$ Compárese el ejemplo al que recurre Casal $(2016,281)$. En él se asume que los bienes son por definición comunes. 
que simpatizamos con la economía libre hemos abandonado su defensa, fundamentalmente, a los economistas. No es que los economistas hayan sido malos defensores. No quiero decir eso. Creo que el problema es que en algún momento la opinión pública demandaba una justificación del mercado que fuera distinta de la mera utilidad, especialmente en el contexto del destape de varios casos de colusión.

La segunda razón, vinculada con la anterior, es el descrédito que casos como los señalados acarrearon al mercado, que desde entonces comenzó a ser ampliamente considerado como un sistema de anarquía comercial en el que los actores más poderosos se aprovechan sistemáticamente de los actores menos poderosos (básicamente, los consumidores) para poder aumentar ilegítimamente sus ganancias. Esto puso en tela de juicio, a la larga, el hecho mismo de ganar dinero, pues llegado un punto es difícil distinguir entre las ganancias que podríamos llamar legítimas y el margen ilegítimo que los productores, empresarios, entre otros, obtienen de modo fraudulento a través de la colusión u otras prácticas semejantes.

Por este derrotero, la condena del mercado como mecanismo de asignación de bienes se consuma cuando se concluye que, en realidad, esas prácticas no son aisladas, sino que son sistemáticas y responden a la misma lógica del mercado, que alienta la avaricia, la codicia, el egoísmo y otras disposiciones igualmente viciosas. Así, al día de hoy, desde el punto de vista de la opinión pública, y pese a los resonantes éxitos que se ha anotado en nuestro país durante los últimos 30 o 40 años, la economía de mercado se encuentra moralmente en bancarrota. No se trata sólo, creo, de que la gente piense que la prosperidad alcanza muy lentamente a los que tienen menos, sino que, más aún, sencillamente no considera decente seguir participando de un sistema tan pretendidamente inmoral. Esta reacción es normal. Después de todo, la mayoría de la gente no estaría dispuesta, seguramente, a enriquecerse a costa del prójimo, o no al menos de modo sistemático. Al final, es de suponer, se hastiaría. En este contexto, la apelación a la utilidad y eficiencia del mercado no sólo resulta fútil, sino incluso contraproducente.

La situación es desalentadora, no únicamente porque la gente parece haber olvidado las injusticias a que de modo invariable da lugar un creciente estatismo, sino porque además corre el riesgo de recordarlas cuando ya sea tarde, cuando la prosperidad que trajo el sistema de mer- 
cado quede atrás y los defensores del socialismo u otras formas de estatismo intenten granjearse la adhesión de los ciudadanos alegando que el fracaso de sus propias políticas se deba al sabotaje de los capitalistas, a la gradualidad de sus propias reformas, al imperialismo norteamericano, a la conquista de América o a todas esas cosas juntas.

¿Por dónde partir, entonces?

Creo que lo primero es combatir la caricatura que les gusta difundir a los enemigos de la economía de mercado; esto es, que el mercado es un sistema de anarquía comercial que favorece al más fuerte y alienta la aparición de disposiciones viciosas.

Sin embargo - y por mucho que les pese a los difusores de tales caricaturas-, allí donde no existen ciertas reglas, como dice Hayek, generales, universales y abstractas, no puede haber mercado. El mercado es un epifenómeno de tales reglas y, más precisamente, de las reglas que permiten el intercambio libre.

Como muchos probablemente considerarán que incurre en un oxímoron quien niega que los intercambios libres sean anárquicos, habrá que añadir inmediatamente a la explicación anterior que nadie tiene libertad para perjudicar a otros, y que la existencia misma del mercado depende de esa restricción. Quienes niegan que esa restricción sea relevante confunden el mercado con el pillaje. Pero $-\mathrm{y}$ como debería ser evidente - en un mundo donde el pillaje fuera lícito o el fraude fuera universalmente practicado, no podría haber mercados, pues no podría haber tampoco intercambios libres.

De este modo, podemos decir que el principio fundamental del mercado libre es que cada individuo tiene derecho a cerrar los acuerdos que estime pertinentes en la medida en que con ello no perjudique a otros. Así, no son adquisiciones realizadas en un mercado libre, por ejemplo, las anexiones de territorios africanos a los imperios coloniales europeos durante el siglo XIX, por mucho que la demanda de materias primas se hiciera sentir con fuerza en los productores europeos de la época. Había mercados allí donde esas materias primas se vendían, pero no en África donde eran mal habidas. Tampoco son tratos realizados en un mercado libre los acuerdos que alguien se resigna a celebrar con la mafia para evitar represalias, el chantaje ni otros por el estilo.

Con todo, la formulación que he dado — cada individuo tiene derecho a cerrar los acuerdos que estime pertinente en la medida en 
que con ello no perjudique a otros - todavía adolece de ciertas ambigüedades que intentaré ir aclarando de a poco. Mientras, quiero llamar la atención acerca de la compatibilidad que existe entre esa regla y esta otra, más general: cada uno tiene libertad para obrar del modo que estime conveniente mientras con ello no perjudique a los demás o, si se quiere, más sucintamente, la libertad de cada uno termina donde empieza la de los demás.

No creo que sea necesario detenerme a justificar esta regla más general. El socialismo, como proyecto moderno que pretende corregir y ampliar el liberalismo, tiene una vocación emancipadora y, al menos en principio, estará de acuerdo con ella. Mis diferencias con el socialismo tienen que ver con qué es lo que debe entenderse por "libertad". No me ocuparé del socialismo, pues, creo, varias de las críticas que he dirigido al igualitarismo se aplican también a él. Los cabos sueltos por lo que al socialismo se refiere los ataré en breve, cuando toque el problema del lucro y del justo precio. En consecuencia, creo que este principio sólo podría incomodar a un conservador; esto es, a alguien que crea que un orden político debe ocuparse no solamente de arbitrar reglas para hacer posible la convivencia pacífica, sino, además, de promover una determinada concepción de la felicidad, incluso a despecho de la opinión de los propios ciudadanos. Por esta razón $-\mathrm{y}$ como ponen de manifiesto las diferencias con las posturas que aquí he llamado "conservadoras"creo que la corrección del principio que he formulado descansa, en último término, en la idea de que los individuos deben tener derecho a decidir soberanamente cómo conducirán sus vidas y en la de que, a fin de cuentas, una condición de posibilidad del sentido de la propia vida es que se permita a cada uno vivir la suya según su propio juicio y opinión. Volveré sobre algunos de estos problemas al final.

Pues bien, en el entendido de que los individuos son libres para decidir por sí mismos sin otra restricción que el derecho equivalente de los otros, ¿cuándo es justo un intercambio? Respondo: cuando es voluntario.

Alguien — que no fuera contractualista, evidentemente- podría intentar impugnar esta equivalencia entre voluntariedad y justicia mediante un ejemplo: el trabajador asalariado que acepta de mala gana una oferta de trabajo porque no tiene una mejor alternativa. 
Pues bien, la pregunta es: ¿Por qué habríamos de decir que este acuerdo no es justo? Casos como éste son difíciles y tienen varias aristas y me referiré a algunas de ellas después. Por ahora sólo quiero discutir una posible línea de argumentación que me parece insostenible, a saber, aquella que arguye que el trato sería voluntario pero injusto porque el salario que se acuerda es objetivamente bajo en relación con el trabajo realizado. Esta línea de argumentación suscita la dificultad de dar con un baremo o medida del valor (de cambio) del trabajo (o de un servicio o de un bien) con independencia de la apreciación que del mismo tengan las partes.

Pero, ¿qué criterio diferente o independiente de la voluntad de cada contratante puede ofrecerse para juzgar la rectitud de un acuerdo? Si decimos, por ejemplo, que es la cantidad de trabajo "socialmente necesario", ¿cómo debe interpretarse la fórmula "socialmente necesario" al margen del conjunto de preferencias de la gente?

El problema, por consiguiente, no es si existe un precio justo "objetivo" que pueda determinarse haciendo abstracción de las preferencias de los contratantes, sino, tan sólo, si éstos han obrado voluntariamente, pues es el querer de las partes el que reduce bienes o servicios heterogéneos a un denominador común. Por tanto, en el caso del trabajador asalariado la pregunta no es si el salario es "justo" de acuerdo con algún criterio abstracto, sino si este último ha contratado voluntariamente hic et nunc. Si así ha sido, entonces el salario es justo. El único modo de impugnar la validez de un contrato sería, entonces, probando que "en realidad" el trabajador no ha consentido voluntariamente en él. Volveré enseguida sobre este problema y sobre lo que se ha llamado "sueldo ético".

Permítaseme, entonces, recapitular todo lo que he dicho hasta el momento en la formulación de las siguientes reglas, que se inspiran en las teorías de la justicia de Kant y de Nozick:

- Todos los individuos son naturalmente libres.

- La medida de la libertad de cada uno es el respeto de la libertad de los demás.

- Todo individuo, por tanto, tiene derecho a obrar como considere que es mejor siempre y cuando con ello no perjudique a otros.

La aplicación de estas tres reglas al uso de los bienes y servicios produce estas otras reglas: 
- La apropiación de una cosa que no tiene dueño es lícita. ${ }^{15}$

- Las transferencias que tengan lugar por medio de intercambios voluntarios son lícitas. ${ }^{16}$

Habrá quienes consideren que estas reglas son frías, impersonales y constituyen una forma de consagrar el individualismo. Otros lamentarán, por el mismo motivo, que no reflejen los principios de solidaridad que debiera existir entre los miembros de una sociedad.

Sin embargo, objeciones como ésas olvidan el agobio que puede significar intentar establecer legalmente lazos de solidaridad entre individuos que no tienen relaciones afectivas de ningún tipo entre sí. La familia, por ejemplo, es un pésimo modelo de construcción de una sociedad como la nuestra, en que viven miles o incluso millones de personas, pues la familia efectivamente se mantiene unida por lazos de afecto que sobrepasan con mucho a las reglas de respeto mutuo en las que se basa el derecho. Por eso Hegel, por ejemplo, decía que la importancia del derecho se deja sentir entre los miembros de una familia únicamente cuando la familia se disuelve (por ejemplo, al disputar los herederos por la división de la herencia, al tener lugar un divorcio, al abandonar el padre a los hijos y demandarle estos alimentos, etcétera). Antes de eso el derecho no se deja sentir porque el afecto y amor mutuos suplen toda necesidad, liman las asperezas y avienen continuamente a los miembros de una familia.

En este sentido, no hay continuidad entre la familia y la sociedad civil, y el intento por homogeneizar sus reglas resulta siempre asfixiante para los que lo padecen. Por eso, como decía Aristóteles, la familia no es una ciudad en miniatura ni la ciudad una casa a gran escala.

${ }^{15}$ Es decir, en un principio los bienes son res nullius, no absoluta sino potencialmente (es decir, carecen en principio de dueño pero no por principio, de suerte que pueden llegar a ser propiedad de alguien). Puesto que, por otra parte, todos los individuos tienen una igual libertad a tomar bienes del mundo, no puede ocurrir que las sucesivas apropiaciones dejen a alguien sin nada. Nozick resuelve este problema diciendo que las apropiaciones originarias son lícitas cuando con ella no se empeora la situación de otros (estipulación de Locke), y que "empeorar" significa no suprimir las posibilidades de usar cosas de la misma clase de la que yo me apropio. La distinción de Kant entre posesión nouménica y posesión fenoménica permite ofrecer una solución parecida por lo que al estado de necesidad respecta.

${ }^{16}$ Se entiende que los intercambios que no deben ir en perjuicio directo de otros en virtud del precepto general que dice que mi libertad termina donde empieza la de los demás. 
Por otra parte, las pretendidas frialdad e inhumanidad de estas reglas permiten no sólo que cada uno disponga de un ámbito de libertad individual para llevar a cabo su proyecto de vida como estime conveniente, sino, que además, como observa Hayek, permiten recabar la colaboración de otros sin necesidad de que nos pongamos previamente de acuerdo acerca de los fines últimos de la cooperación social. Por eso, los que tenemos simpatías liberales nos identificamos con estas reglas que permiten a cada uno escoger el modo de vida que prefiera, mantener las relaciones de afecto a que le inclinen sus preferencias y, en fin, poder prescindir del permiso de cualquier otro para decidir qué hacer, cómo, con quién, cuándo, etcétera.

Las libertades económicas son parte integrante de este conjunto de libertades. Los chilenos ahora las subestimamos porque aún contamos con ellas y, supongo, las damos por descontadas. Pero, imaginémonos que el proceso de establecer un sistema de educación superior público, gratuito y de calidad - es decir, el proceso de estatizar la educaciónnos conduce al escenario de establecer cupos de postulantes para las distintas carreras. Supongamos, además, que yo quiero ser geólogo y soy el $\mathrm{n}+1$ de los $\mathrm{n}$ cupos que abrió el Estado. Supongamos además que usted es geólogo y está dispuesto a enseñarme a cambio del pago de ciertos honorarios. En ese escenario, pese a estar ambos de acuerdo, el Estado no permitiría que cerráramos el trato. $\mathrm{O}$ usted tendría que enseñarme de modo clandestino (eso será una consecuencia inevitable de que ahora este trato que celebramos sea proscrito) o yo tendría que correr el riesgo de hacer la inversión para después tener unos conocimientos que no puedo acreditar, pues el Estado no me dará certificación alguna. ¿No sería este escenario injusto? ¿Y no es significativo que esta injusticia sólo pueda ser evitada mediante un sistema educacional abierto; esto es, un sistema en que alumnos y profesores (o alumnos y universidades) tienen la posibilidad de elegir libremente qué estudiar, cuándo, bajo qué condiciones?).

Alguno querrá tal vez acusarme de alarmista, de hacer campaña del terror, de recurrir a la falacia de la pendiente resbaladiza y otras cosas por el estilo. Evidentemente, en la práctica hay grados y niveles intermedios. La libertad puede estar restringida en unos sentidos pero no en otros. Aquí sólo quiero llamar la atención sobre las consecuencias que se siguen de ciertos principios. Si el lucro es deleznable y tenemos 
universalmente derecho a ciertas prestaciones de calidad provistas por el Estado, ¿por qué no se puede entonces proscribir derechamente toda la oferta privada de esas prestaciones? ¿Por qué no dar al Estado el monopolio de la salud, la educación, las pensiones, la vivienda, el vestido, las comunicaciones, el transporte y la alimentación? ¿Por qué no decir, en último término, que si dos personas convienen libremente en un trato no podrán cerrarlo porque ya no se les reconocerá ese derecho? ¿Qué argumentos tienen los detractores del lucro ante esta consecuencia de su propia postura? Si sólo lo quieren prohibir para ciertas actividades, pero no para otras, ¿entonces por qué dicen que el lucro es malo? Si sólo los detienen consideraciones económicas - por ejemplo, que su propuesta nos abocaría a la quiebra-, ¿por qué habrían ahora de rebajarse a avenirse a vulgares argumentos economicistas? ¿No era cierto acaso el fiat iustitia et pereat mundus?

\section{ALIENACIÓN, AFÁN DE LUCRO Y JUSTO PRECIO}

El mercado, idealmente, es el reflejo de todas las elecciones que libre y voluntariamente han realizado los individuos. Es, además, un mecanismo descentralizado de asignación de valor económico, pues, idealmente, estos valores reflejarán las preferencias de los individuos.

Se suelen escuchar quejas acerca de la inmoralidad que supone la diferencia de ingresos: unos ganan mucho mientras que otros ganan poco. Por ejemplo, los futbolistas en relación con los profesores de filosofía.

Estas quejas, sin embargo, pasan por alto el hecho de que el sueldo que gana un futbolista de las grandes ligas es mayor al de un filósofo destacado — supongamos, Habermas-, porque el común de la gente prefiere destinar parte de su dinero y su tiempo a ver un clásico del fútbol antes de que escuchar una conferencia de Habermas.

¿Es deplorable que así sea? No me lo parece, aun cuando crea que la filosofía sea mucho más importante y edificante que el fútbol. Como esta convicción acerca de la superioridad de la filosofía coexiste con otras - como que se debe permitir a las personas tomar sus propias decisiones; que la filosofía, como cualquier otra actividad, sólo resulta edificante cuando es realizada de modo libre y voluntario o, en fin, que el valor económico es tan sólo un aspecto del valor de las cosas y no 
representa, por lo mismo, todo el valor de algo (por ejemplo, su valor cultural o estético)-, no me parece deplorable que un jugador de las grandes ligas gane más dinero que un filósofo porque la gente prefiere el fútbol a la filosofía.

Aquellos que desearían organizar la sociedad desde alguna perspectiva unificada tienden a considerar la distribución del mercado como defectuosa y necesitada, por lo mismo, de alguna corrección. Así, por ejemplo, algunos seguramente consideran que la gente no sabe realmente lo que le conviene y querrían disponer las cosas de tal modo que los violinistas ganaran más dinero que los cantantes de hip-hop, o desearían inducir a la gente a escuchar un tipo particular de música obligando a las emisoras a transmitirla, y otras cosas por el estilo.

Es paradójico que esa visión aristocrática y paternalista, que supone que el grueso de la gente está equivocada acerca de lo que resulta mejor para ella sea sostenida en ocasiones por personas que reclaman por el presunto déficit democrático de nuestra propia sociedad.

Por alguna razón, la gente caería en la más abyecta alienación desde el momento mismo en que pisa un centro comercial pero se eleva a las alturas de los grandes estadistas a la hora de participar de consejos ciudadanos, asambleas y cosas por el estilo. Pero, ¿no resulta contradictorio afirmar, por una parte, que los agentes están alienados y no saben lo que quieren en una instancia, pero tomarlos como competentes y juiciosos en otra? ¿No se trata acaso de los mismos agentes?

Algunos querrán sostener —abandonando con ello la argumentación anterior para ensayar una nueva - que existe una diferencia: en las asambleas ciudadanas y otras instancias deliberativas, los individuos adoptarían un punto de vista universal o "ciudadano" o "público" (o algo por el estilo), mientras que al comprar y vender se estarían necesariamente comportando de modo mezquino, interesado, usándose mutuamente.

Entiendo que muchas de las reservas en contra del mercado tienen que ver con esta supuesta instrumentalización en que incurrirían los individuos a la hora de contratar. Así, mientras la democracia sería una instancia de respeto y reconocimiento mutuo, el mercado sería por definición una instancia de instrumentalización mutua.

Supongo que esa representación del mercado es la que subyace, en lo esencial, al eslogan contra el lucro, pues lo que se alega es, más o menos, que no se debe lucrar con derechos como, por ejemplo, la edu- 
cación, la salud, la vivienda, la alimentación o el transporte; y que al lucrar yo estoy utilizando a otro, explotando su necesidad, procurándome una ganancia por medio de prestaciones que son tan fundamentales que deberían ser provistas a todos gratuitamente, ya sea porque conducen a la felicidad o son condición de ella, porque tienden a evitar una distribución desequilibrada del poder, o porque permiten la consecución de cualquier otro fin que se estima socialmente valioso.

El moralismo de esta afirmación es tanto que seguramente no se la puede sostener sin hipocresía. ¿Cómo piensan procurarse los bienes aquellos que la profesan? Como no creo que los detractores del lucro estén al mismo tiempo en contra de la división del trabajo, supongo que no esperan procurarse todo ellos mismos y, en consecuencia, están dispuestos a que exista un sistema de intercambio basado únicamente en la generosidad (el mero trueque no sirve, evidentemente, pues al permitir el cambio de un bien por otro se corre el riesgo de que los contratantes lo hagan esperando ganar algo con él, esto es, lucrar). Si no, la única alternativa que queda es un sistema centralizado de asignación de bienes. Pero entonces, ¿cuál sería el incentivo para trabajar? ¿La generosidad universal? ¿Qué pasaría con aquellos que intenten contratar por su cuenta? ¿Se los toleraría? Y, por repetir los argumentos de Von Mises y Hayek, ¿cómo se sabrá qué producir, cuánto y a quién dárselo?

No sé cuál de las dos posibilidades resulta más inverosímil. De todos modos, es deprimente que alguien considere seriamente la segunda después del espectáculo ofrecido por los "socialismos reales" durante el siglo XX.

Pero más allá de estas consideraciones, el argumento en contra del lucro es o falso o ininteligible sin otras tesis auxiliares sumamente controvertidas. Falso, porque al pagar a alguien por un servicio que me presta yo, precisamente, no lo estoy sólo instrumentalizando o, como diría Kant, utilizando como un mero medio. De hecho, al acordar libremente con él un trato y cumplir con mi parte del mismo estoy, al revés, tributándole el reconocimiento que como persona se merece en esta circunstancia concreta. ${ }^{17}$

${ }^{17}$ Honneth, por ejemplo, admite este reconocimiento cuando afirma que la “equiparación de Lukács entre intercambio de mercancías y reificación” resulta poco convincente, "dado que, por cierto, en el intercambio económico generalmente el par en la interacción permanece presente al menos como persona jurídica" (Honneth 2007, 130). 
Piénsese en las tres siguientes situaciones: en una usted es taxista. Yo le apunto con una pistola y le exijo que me lleve a mi destino; en la segunda le pido que me lleve a mi destino y una vez allí me voy sin pagarle; en la tercera le pido que me lleve, usted lo hace y yo le pago por ello. Pues bien, ¿en cuál de ellas he obrado yo mal contra usted? Evidentemente en aquellas en que no le he pagado. He obrado bien únicamente en la tercera, esto es, en aquella en que usted ha lucrado conmigo o gracias a mí. ¿Cuál es la diferencia entre todas esas situaciones? En las dos primeras yo lo he usado a usted como un mero medio. En la tercera lo he tratado como un medio pero no como un mero medio. ¿Por qué? Porque le he pagado. El pago expresa aquí mi reconocimiento a su libertad, su trabajo, su propiedad. Evidentemente, hablar del lucro de forma indiscriminada encubre esta diferencia entre usar y meramente usar a alguien. Sólo el segundo caso es inmoral o ilícito. Por esta razón, el argumento contra el lucro es falso.

Supongo que el detractor del lucro podría replicar que no se refiere a cualquier ganancia, sino a la ganancia excesiva. Después de todo, si usted me cobrara cien mil pesos por llevarme dos cuadras más allá, me habría usado como un mero medio. Su ganancia habría sido excesiva. Esto nos remite, nuevamente, al problema del "justo precio". Pero, como ya adelantaba, ¿cómo resolver cuál es el justo precio de algo más allá de las preferencias (agregadas) de los individuos? Creo que, descartada las "horas de trabajo socialmente necesarias", sólo queda un factor posible: la necesidad.

\section{LIBERTAD, NECESIDAD Y ESTADO}

He comenzado el apartado anterior señalando que el mercado "idealmente" es el reflejo de todas las elecciones que libre y voluntariamente han realizado los individuos.

Ahora quisiera detenerme en el adverbio "idealmente", que me permitirá introducir importantes matices en mi argumentación.

¿Por qué he utilizado ese adverbio? Básicamente, porque soy consciente de que la condición que he formulado para la rectitud de los intercambios - es decir, la voluntariedad - no se cumple de modo cabal en todos los casos. 
Comencemos con un ejemplo extremo: un asaltante me amenaza con un arma y me pide que le entregue el dinero que llevo conmigo. Yo, de mala gana, lo hago. Pues bien, en este caso, ¿he obrado voluntariamente? Desde cierto punto de vista sí, pues al final he accedido a entregarle el dinero al asaltante. Yo he decidido realizar el acto. Pero por otra parte es evidente que no he obrado voluntariamente, pues en la práctica no me quedaba más opción. He obrado de mala gana. Pues bien, en realidad he obrado en parte voluntaria y en parte involuntariamente, y seguramente más del segundo modo que del primero.

Lo cierto es que muchas veces — quizás la mayoría - obramos en parte voluntaria y en parte involuntariamente. Esto es lo que Aristóteles llamaba los actos mixtos de voluntario con involuntario. ${ }^{18}$ El ejemplo que él pone es el del capitán de navío que, en la tormenta, se ve en la necesidad de arrojar la carga por la borda para no naufragar. En cierto sentido el acto es voluntario, pues el capitán ha querido y decidido arrojar la carga. En otro, dice Aristóteles, es involuntario, pues, en términos absolutos, el capitán no quiere tirar la carga.

Apliquemos esta distinción a un ejemplo menos extremo que el del asaltante: el del trabajador asalariado mencionado antes. El trabajador que acepta trabajar por un sueldo de subsistencia, ¿de qué modo obra? Creo que lo más sensato es reconocer que obra, como decían los escolásticos, con voluntad imperfecta, esto es, en parte voluntaria y en parte involuntariamente.

¿Cómo afecta esta categoría intermedia, este tertium quid entre lo voluntario y lo involuntario, a lo que aquí he venido sosteniendo?

El principio general es que los intercambios o, en términos más generales, los acuerdos son justos si es que son voluntarios (volenti non fit iniuria, al que consiente no se le hace daño). ${ }^{19}$

A partir de este principio y de la constatación de que la voluntariedad tiene grados, podemos ahora formular la siguiente regla general: "Mientras menos perfecta la voluntad, menos justo el acuerdo". Esto es, mientras mayor la involuntariedad - expresada en reticencia, resignación o lo que corresponda-, menos justo es el acuerdo.

${ }^{18}$ Aristóteles, Ética a Nicómaco (2002, III, 1).

${ }^{19}$ Respecto de este punto, compárese, por ejemplo, a Vitoria (2006, 92): “En las conmutaciones humanas no es suficiente para la justicia conmutativa el que por ambas partes sea algo absolutamente voluntario, sino que es necesario que no tenga mezclado algo de involuntario". 
Pues bien, ahora tendré el atrevimiento de introducir ciertas correcciones en la teoría de la justicia de Nozick, de modo que refleje el hecho de que la voluntad en ciertas circunstancias es imperfecta.

Al formular su teoría de la justicia, Nozick afirma que nadie tiene derecho a un bien sino en virtud de una apropiación originaria lícita, de los intercambios voluntarios o de la restitución y/o indemnización que se le deba como consecuencia de la comisión de un delito en su contra. Cierra su teoría insistiendo en que nadie tiene derecho a un bien excepto por aplicaciones repetidas de las reglas anteriores.

Estas reglas generales son, evidentemente, ciertas. El derecho privado no es, en lo esencial, más que un desarrollo y determinación de estos principios generales. El problema de la teoría de la justicia de Nozick radica, a mi juicio, no en esas reglas, sino en la insistencia en que no hay más títulos legítimos de adquisición.

En razón de lo dicho acerca de los grados de voluntariedad, esta regla debe ser abandonada en favor de esta otra (o alguna equivalente):

- "Los que padecen necesidad tienen derecho a los bienes suficientes que les permitan aliviar esa necesidad".

Nozick clausura su teoría de la justicia de tal modo que corta todos los vasos comunicantes entre la justicia conmutativa y la justicia distributiva. ${ }^{20}$ La constatación de que la voluntariedad sea susceptible de grados permite restablecer los puentes entre una y otra forma de justicia y hacerse cargo del problema de la necesidad, lo que Nozick hace de modo muy parcial y, a fin de cuentas, insatisfactorio. ${ }^{21}$

Pues bien, hay que aliviar la situación de los individuos que padecen necesidad. Pero, ¿quién debe asumir esa tarea?

Es cierto, por ejemplo, que los empresarios tienen un deber moral de mejorar, en la medida de sus posibilidades, las condiciones de sus trabajadores. Así, deben intentar establecer condiciones que permitan

${ }^{20}$ Esto también se explica por la noción que tiene Nozick de voluntariedad. Véase $(1988,255)$.

${ }^{21}$ Es falso, con todo, que la teoría del título válido de Nozick nos obligue a desentendernos de toda forma de necesidad. Lo que él llama la "estipulación de Locke" obliga a los individuos a hacerse cargo de la necesidad que sea consecuencia de sus adquisiciones originarias o derivativas. Asimismo, Nozick admite que puede haber una responsabilidad, incluso social, por injusticias históricas. Esto comprende, evidentemente, la necesidad que es consecuencia de ese tipo de injusticias. 
a sus trabajadores consentir en el trato que cierran con él o con la empresa con voluntad perfecta o, en su defecto, lo más perfecta posible. Sin embargo, no creo que la responsabilidad moral por la mejora de la condición general de los trabajadores recaiga, en último término, en los empresarios, en tanto que tales. En el caso de que los empresarios robaran sistemáticamente al trabajador el valor de su trabajo - esto es, pagaran por él a sus trabajadores menos del justo precio-, su obligación sería la de restituirles el valor de lo injustamente apropiado, pero no mejorar sus condiciones generales, pues quien restituye no está, en realidad, mejorando la posición de otro.

Supongo, por tanto, que aquellos que entienden que el empresario en particular tiene el deber de mejorar las condiciones del trabajador, lo creen porque entienden que el primero se queda con parte del valor del trabajo del segundo o los defrauda sistemáticamente de cualquier otro modo. Pero, ¿hasta qué punto puede considerarse verosímil la idea de que el empresario se queda con la plusvalía de la fuerza de trabajo de sus trabajadores? Si el criterio para medir el valor de cambio de los bienes es la "estimación común" (o, si se prefiere, la oferta y la demanda) y no las horas de trabajo socialmente necesarias para producir un bien, entonces la idea del robo sistemático de la plusvalía a los trabajadores no puede sino ser falsa.

Si la teoría del valor trabajo es falsa $-\mathrm{y}$ lo es-, entonces, el "sueldo ético" - esto es, lo que podríamos decir que el empresario está moralmente obligado a pagar - es el precio de mercado. Y si ese sueldo es bajo, la diferencia necesaria para dejar a esa gente por sobre el umbral de la necesidad debe ser proporcionada, no por el empresario, sino por el Estado a través de los programas que disponga para ese fin, con cargo a las rentas generales. Dicho de otro modo, ese coste debe soportarlo la sociedad en su conjunto o, más precisamente, los miembros de la sociedad que tengan mejor situación económica.

Bajo el modelo aquí esbozado, la sociedad, a través del Estado, debiera preocuparse de los que padecen necesidad. No es necesario que el Estado asuma las tareas que le impone este deber directamente. Además de los argumentos de eficiencia que a este respecto se pudieran esgrimir, existe una razón de principio: la razón para admitir la actividad del Estado más allá de las labores de defensa y jurisdicción tiene que ver con la creación de las condiciones que garanticen que los individuos 
puedan contratar con voluntad perfecta. Y así como este principio abre la puerta a la expansión del Estado más allá del Estado mínimo, al mismo tiempo le cierra la puerta a cualquier Estado mayor que el Estado subsidiario, en la medida en que le fija ciertos límites infranqueables a la extensión de sus competencias: dicha extensión se prolonga hasta allí donde los individuos pueden valerse por sí mismos, pues se la otorgan precisamente con ese fin. Las prestaciones y servicios que el Estado debe procurar a los individuos deben, por ello, ser concebidos como transitorios y motivados por razones de emergencia; deben ser concebidos de tal modo que se ha de esperar de ellos su paulatina desaparición, aun cuando, por otro lado, pueda ocurrir que esa desaparición nunca ocurra en los hechos.

Lo que no podría suceder es que el Estado, ya sea por iniciativa de sus agentes y funcionarios, ya por clamor popular, reclamara para sí la realización de actividades que exceden el alivio de la necesidad. Menos aún le resultaría lícito reclamar el monopolio de actividades diferentes de la defensa y jurisdicción con vistas a la promoción de algún fin político cualquiera como, por ejemplo, la igualdad. La razón de ello - ya adelantada - es que ese monopolio exigiría tarde o temprano prohibir los acuerdos e intercambios que dos personas libre y voluntariamente quieran celebrar.

El Estado subsidiario es el único compatible con los principios formulados más arriba. Por consiguiente, el Estado subsidiario es el único que puede legítimamente imponerse a los individuos. ${ }^{22}$

Pues bien, y en este esquema, ¿dónde ha quedado la igualdad económica?

Permítaseme plantear antes la siguiente pregunta: ¿Qué tiene que ver la necesidad con la igualdad o, más precisamente, con el igualitarismo?

Rousseau cree que existe una relación esencial entre ambas y por eso afirma que la consecución de la igualdad política exige, por lo que a la riqueza concierne, "que ningún ciudadano sea lo bastante opulento

${ }^{22}$ Podría ocurrir, naturalmente, que algunos individuos que, por ejemplo, recelan de la provisión de servicios por parte de privados o no tienen temor del clientelismo político quisieran que el Estado y sólo el Estado los proveyera de ciertos servicios. En ese caso, creo que es justo permitirles acogerse a un régimen totalmente público, es decir, estatal. Lo que no pueden hacer, sin embargo, es intentar arrastrar a los demás consigo a ese régimen. 
para poder comprar a otro, y ninguno lo bastante pobre para ser constreñido a venderse" (Rousseau 2000, 76).

Sin embargo, si un ciudadano no padece necesidad, ¿por qué se iba a ver obligado a venderse? Si ningún ciudadano padece necesidad, ¿por qué iba a ser necesario fijar un límite máximo a lo que otros pueden tener? ¿Y no revela todo ello, en fin, que la igualdad, como afirma Raz, nos importa, no por ella misma, sino por otras preocupaciones que subyacen a los principios igualitarios, como el hambre, la necesidad, etcétera? (Raz 1988, 240).

Es importante subrayar que, aunque puedan estar vinculados en ciertos respectos, la eliminación de la igualdad es un fin político diferente de la eliminación de la necesidad. Aquí he intentado abogar por el segundo en contra del primero. He intentado demostrar que el alivio de la necesidad es no sólo compatible, sino demandado precisamente por los principios más generales de justicia. He intentado demostrar, además, que éste no es el caso en lo que a la igualdad económica respecta. Por tanto, en todo aquello que necesidad e igualdad económica no estén directamente vinculadas, la igualdad económica debe ser abandonada como objetivo político compatible con la justicia.

\section{CONCLUSIONES}

No se me oculta que alguien podría intentar objetar mi posición "suficientarista" - por emplear el anglicismo al uso- pidiéndome que trazara la línea en que acaba la necesidad. Pues bien, no tengo ningún problema en conceder que la definición de ese umbral resulta problemática y que merece ser objeto de diferentes discusiones políticas. Pero la definición de ese umbral no puede hacerse en abstracto, con prescindencia del asunto de que se trate, las condiciones de una sociedad, circunstancias varias.

Tarde o temprano, toda filosofía se enfrenta a esta dificultad: que no puede ser resuelta por principios a priori o por reglas generales. Hay que decidir prudencialmente, $\mathrm{y}$, llegado este punto, lo más que pueden hacer los principios por nosotros es orientarnos.

Así, por ejemplo, si un igualitarista no comulga con un igualitarismo estricto, ¿dónde debe fijar la línea en que la desigualdad es tolerable de la que no? Lo mismo vale para un "prioritarista" y para todos los 
demás "ismos" que respecto de este problema, o cualquier otro, puedan aparecer en filosofía política. ${ }^{23}$

Los principios que aquí he defendido promueven un Estado subsidiario y no paternalista. Ese Estado -y no otro- creo que es el único que respeta la libertad de los individuos, esto es, su libertad para determinar soberanamente el modo de vida que quieran llevar mientras con ello permitan a los demás hacer lo mismo. Por ese motivo, este Estado debiera constituir el modelo que sirva de orientación general al diseño de las instituciones y políticas públicas. El que luego haya que determinar las instituciones concretas y su funcionamiento es no sólo inevitable, sino, además, deseable. Esa indeterminación abre el espacio para la discusión política y a modos particulares de realizar la libertad a nivel social.

Hasta el momento, estos principios no han sido defendidos de modo consistente por ningún partido político en nuestro país. Tenemos, por la derecha, partidos conservadores que defienden el libre mercado $\mathrm{y}$, por la izquierda, partidos progresistas que defienden la libertad en todos los otros ámbitos. No creo que a la larga sea posible defender el libre mercado y mantener una actitud paternalista en los temas morales. Quienes lo han hecho así han permitido que la defensa del mercado libre quede, paradójicamente, asociada a las posturas más reaccionarias y autoritarias en lo que a moral sexual, derecho de familia y demás problemas afines se refiere. Con ello han renunciado al potencial emancipatorio que tiene el liberalismo económico, el cual ha quedado identificado con las agendas paternalistas que, en muchos casos, se oponen derechamente al reconocimiento de ciertos grupos y, en ese sentido, a la igualdad de trato.

No creo, por otro lado, que resulte tampoco consistente defender el derecho de los individuos a llevar el estilo de vida que quieran (por

${ }^{23}$ Compárese, por ejemplo, la respuesta de Kenworthy, un autor igualitarista, a esta dificultad: "John Nye asks: 'What measure of inequality do Kenworthy and Anderson wish to observe that would lead them to say $O k$. No more needs to be done?' My response: There is no such precise measure or amount, and in my view it would be silly to offer one. My judgment about whether I would favor reducing the existing level of income inequality is based on how much it has increased and why, what seems feasible (taking into account, among other things, prior levels of inequality and levels achieved by other countries), and what the benefits and costs of reducing the existing level might be" (Wilkinson et al. 2009, 43). 
ejemplo, a contraer matrimonio con personas del mismo sexo), pero a la vez limitarles o prohibirles incluso la celebración de otros acuerdos en otros ámbitos de la vida.

Como en este momento el curso de los acontecimientos parece favorecer el avance de la última forma de inconsistencia, me ha parecido oportuno quebrar algunas lanzas en favor de la libertad económica.

\section{REFERENCIAS}

Anderson, Elizabeth. 2016. “¿Cuál es el punto de la igualdad?”. En Igualitarismo. Una discusión necesaria, editado por Javier Gallego S. \& Thomas Bullemore L., 45-104. Santiago: Centro de Estudios Públicos.

Aristóteles. 2002. Ética a Nicómaco. Traducido por María Araujo y Julián Marías ( 8 a edición). Madrid: Centro de Estudios Políticos y Constitucionales.

Casal, Paula. 2016. "Por qué la suficiencia no basta". En Igualitarismo. Una discusión necesaria, editado por Javier Gallego S. \& Thomas Bullemore L., 269-301. Santiago: Centro de Estudios Públicos.

Cohen, Gerald Allan. 2011. On the Currency of Egalitarian Justice, and Other Essays in Political Philosophy. Editado por Michael Otsuka. Princeton: Princeton University Press.

Fichte, Johann Gottlieb. 1971. Fichtes Werke. Editado por Hermann Immanuel Fichte. Berlin: Walter de Gruyter.

Fraser, Nancy \& Axel Honneth. 2006. ¿Redistribución o reconocimiento? Traducido por Pablo Manzano. Madrid-A Coruña: Ediciones Morata y Fundación Paideia Galiza.

Hegel, Georg Wilhelm Friedrich. 1986. Werke. Frankfurt am Main: Suhrkamp.

Hirose, Iwao. 2015. Egalitarianism. Abingdon - New York: Routledge.

Honneth, Axel. 2007. Reificación. Un estudio en la teoría del reconocimiento. Traducido por Graciela Calderón. Buenos Aires: Katz editores.

-1997. La lucha por el reconocimiento. Por una gramática moral de los conflictos sociales. Traducido por Manuel Ballestero. Barcelona: Crítica.

Hume, David. 1993. Investigación sobre los principios de la moral. Traducido por Carlos Mellizo. Madrid: Alianza.

Kirzner, Israel M. 1995. Creatividad, capitalismo y justicia distributiva. Traducido por Federico Basáñez Agarrado. Madrid: Unión Editorial.

Kropotkin, Piotr. 2010. La conquista del pan. Buenos Aires: La Malatesta Editorial.

Nozick, Robert. 1988. Anarquía, Estado y utopía. Traducido por Rolando Tamayo. México: Fondo de Cultura Económica.

Parfit, Derek. 1997. "Equality and Priority”. Ratio 1 (3): 202-221. 
Proudhon, Pierre-Joseph. 1985. ¿Qué es la propiedad? Traducido por Rafael García Ormachea. Barcelona: Ediciones Orbis.

Rawls, John. 2002. La justicia como equidad. Una reformulación. Editado por Erin Kelly, traducido por Andrés de Francisco. Barcelona: Paidós.

— 2003. Teoría de la justicia. Traducido por María Dolores González. México: Fondo de Cultura Económica.

Raz, Joseph. 1988. The Morality of Freedom. Oxford: Oxford University Press.

Rousseau, Jean-Jacques. 2000. Del contrato social. Traducido por Mauro Armiño. Madrid: Alianza.

Sher, George. 1987. Desert. Princeton: Princeton University Press.

Van Parijs, Philippe. 1996. Libertad real para todos. Qué puede justificar el capitalismo (si hay algo que pueda hacerlo). Traducido por J. Francisco Álvarez. Barcelona: Paidós.

Vitoria, Francisco de. 2006. Contratos y usura. Traducido por M. I. Zorroza. Pamplona: EUNSA.

Wilkinson, Will, Lane Kenworthy, John V.C. Nye \& Elizabeth Anderson. 2009. Inequality: Facts and Values. Cato Unbound (October). https://www.catounbound.org/print-issue/644.

Zaitchik, Alan. 1997. "On Deserving to Deserve". Philosophy and Public Affairs 6 (4): 370-388. EP 